\title{
Design and Analysis of an Electronic- Geared Magnetless Machine for Electric Vehicles
}

\author{
Christopher H. T. Lee, Member, IEEE, K. T. Chau, Fellow, IEEE \\ and Chunhua Liu, Senior Member, IEEE
}

Abstract-This paper proposes a new electronic-geared (EG) magnetless machine for electric vehicles. The proposed EG machine can offer the multi-tooth bipolar-flux (MTBF) operation for the low-gear (high-torque low-speed) situation, and the single-tooth unipolarflux (STUF) operation for the high-gear (low-torque high-speed) situation. In particular, the balance-position winding arrangement is proposed to enable the machine having balanced flux-linkages. Consequently, the proposed machine operates as the brushless AC machine for MTBF operation, leading to offer smoother torque at the low-gear situation. Meanwhile, it operates as the brushless DC machine for STUF operation, leading to produce better torque density at the high-gear situation. Various performances of the proposed EG machine are analyzed, with emphasis on the validity of electronic gearing. The experimental prototype is also built for verification.

Index Terms-Electronic-geared, magnetless machine, brushless machine, electric vehicle.

Manuscript received January 14, 2016; revised March 23, 2016; accepted April 30, 2016. This work was supported by Hong Kong Research Grants Council, Hong Kong Special Administrative Region, China under Project No. 17200614.

C. H. T. Lee and K. T. Chau are with the Department of Electrical and Electronic Engineering, The University of Hong Kong, Pokfulam, Hong Kong (e-mail: htlee@eee.hku.hk; ktchau@eee.hku.hk).

C. Liu is with School of Energy and Environment, City University of Hong Kong (e-mail: chualiu@eee.hku.hk). 


\section{INTRODUCTION}

ENERGY utilization and environmental protection have become hot research topics in recent years. As one of the most promising solution for improving energy utilization and environmental protection, the development of electric vehicles (EVs) is speeding up [1]-[4]. As the key component of EV technologies, electric machines have to offer high efficiency, high power density, high controllability, wide-speed range, maintenance-free operation, and fault-tolerant capability [5]-[8]. The doubly salient permanent-magnet (DSPM) machine that incorporates the merits of permanent-magnet (PM) machine and switched-reluctance machine has drawn many attentions in the past few decades [8]-[12]. Meanwhile, inheriting the bipolar-flux characteristic and thus resulting in higher power density, the flux-switching PM (FSPM) machine is becoming popular [13]-[16]. On the other hand, to extend the operating range of PM machines, the memory PM machine has been actively developed, which can allow for online pole-changing of PM poles [17], [18]. Although the PM machines have been widely used for EV propulsion, they inevitably suffer from the problems of high PM material cost and difficult PM flux control [19]-[21]. To overcome the shortcomings of PM machines, the advanced magnetless machines, which utilize cost-effective and flux-controllable DCfield windings to replace the PM materials, have become popular recently [22], [23]. In the meantime, in order to cater for different extreme operating situations, the concept of dual-mode operations, which allow the magnetless machines to operate at the low-speed and high-speed conditions, has been proposed [24]. However, the corresponding machines exhibit unbalanced flux-linkages, resulting in high torque ripple, which is intolerable for $\mathrm{EV}$ propulsion.

This paper proposes a new magnetless machine for EV propulsion, which is dubbed the electronic-geared (EG) machine. Unlike the pole-changing techniques that solely involve the change of flux polarities but not the machine nature, the proposed electronic gearing concept instead incorporates the design philosophies from two types of machines. Hence, the proposed EG machine can behave similarly as the two predecessors, namely the multi-tooth bipolar-flux (MTBF) operation and the single-tooth unipolar-flux (STUF) operation. To be specific, the former operation mode can be employed for the high-torque low-speed situation, while 
the latter one for the low-torque high-speed situation. In addition, the balance-position winding arrangement, which can achieve balanced flux-linkages, will be newly implemented in the proposed machine so that the desired torque performance can be achieved. Moreover, the machine will be designed in such a way that the back electromotive force (EMF) waveforms can facilitate both the MTBF and STUF operations. The machine performances will be analyzed thoroughly by using the finite element method (FEM), with emphasis on the validation of the proposed electronic gearing concept. In addition, the experimental setup will be developed for verification.

It should be noted that the proposed machine is not simply shifting the problem from machine itself to power electronics. Actually, the machine has a new structure, which incorporates both the armature winding and DC-field winding in the stator while the rotor just has salient iron poles. With this new machine structure, the armature winding is fed by sinusoidal currents to provide MTBF operation, which is particularly attractive for the high-torque low-speed situation, while the armature winding is fed, by rectangular currents to provide STUF operation, which is particularly attractive for the low-torque high-speed situation. Therefore, the proposed machine can offer the unique feature like a two-stage mechanical gearbox (low-gear and high-gear) using an electronic way which can eliminate the bulky size and transmission loss of physical gears. This electronic gearing concept is absent in literature.

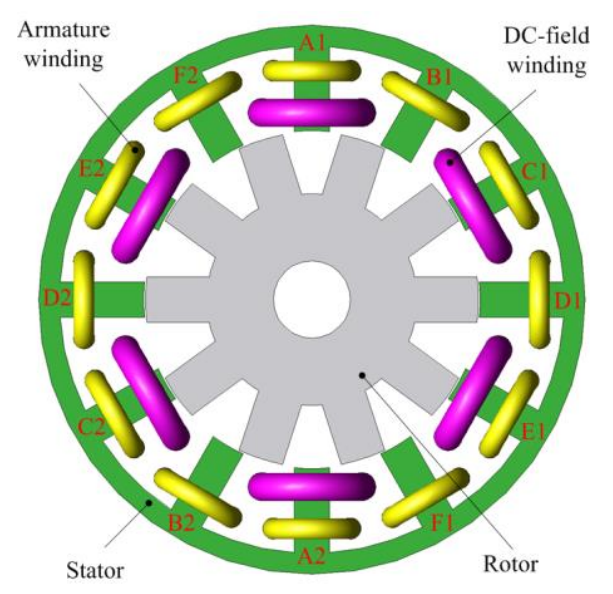

Fig. 1. Electronic-geared magnetless machine structure. 


\section{Electronic-Geared MagnetLess Machine}

\section{A. Machine structure:}

Fig. 1 shows the machine structure of the proposed EG magnetless machine for EV propulsion. It artfully combines the design criteria of the MTBF machine [13] and the STUF machine [10]. Hence, it can inherit the corresponding machine characteristics and possess two different operations, namely the MTBF and STUF operations. The design criteria of the MTBF and STUF machines are both governed by the following general equations:

$$
\left\{\begin{array}{l}
N_{s p}=2 m k \\
N_{s e}=N_{s p} N_{s t} \\
N_{r}=N_{s e} \pm 2 k
\end{array}\right.
$$

where $N_{s p}$ is the number of stator poles, $N_{s t}$ the number of stator teeth per pole, $N_{s e}$ the number of equivalent stator poles, $N_{r}$ the number of rotor poles, $m$ the number of armature phases and $k$ any integer.

Even though the MTBF and STUF machines share the same design criteria in (1), they can be distinguished by the number of armature phases and the number of stator teeth. In particular, with the same numbers of equivalent stator poles and rotor poles, the bipolar-flux and the unipolar-flux machines can be actualized by the multi-tooth and the single-tooth arrangements, respectively. Namely, the multi-tooth least-phase machine is suitable for low-speed operation, while the single-tooth multiphase machine is instead favorable for highspeed operation.

To realize the design criteria of two types of machines simultaneously, the number of equivalent stator poles and the number of rotor poles, i.e. $N_{s e}$ and $N_{r}$, of the two machines should be equalized. However, the derived relationship ends up with an infinite number of solutions because there exist three valuables, namely $m, N_{s t}$ and $k$. Hence, to reduce the degree of freedom and to produce a unique solution, the value of $k$ between the two machines is purposely equalized. Consequently, the relationship can be further derived as:

$$
m^{\prime} N^{\prime}{ }_{s t}=m^{\prime \prime} N^{\prime \prime}{ }_{s t} \quad\left(N_{s t}{ }^{\prime}>N_{s t}{ }^{\prime \prime}\right)
$$


where $m^{\prime}$ and $N_{s t}^{\prime}$ are the numbers of armature phases and stator teeth per pole for the MTBF, respectively, while $m$ '” and $N$ ' ${ }_{s t}$ are the numbers of armature phases and stator teeth per pole for the STUF, respectively. Based on (1) and (2), the fundamental design combinations of the proposed EG machine are obtained as listed in Table I.

\section{TABLE I}

\section{Fundamental Design CombinAtions}

\begin{tabular}{cccccccc}
\hline \hline$k$ & $m^{\prime}$ & $N_{s t}^{\prime}$ & $m{ }^{\prime \prime}$ & $N^{\prime}{ }_{s t}$ & $N_{s e}$ & $N_{r}$ & $N_{r}$ \\
\hline 1 & 3 & 2 & 6 & 1 & 12 & 14 & 10 \\
1 & 3 & 4 & 6 & 2 & 24 & 26 & 22 \\
1 & 4 & 2 & 8 & 1 & 16 & 18 & 14 \\
2 & 3 & 2 & 6 & 1 & 24 & 28 & 20 \\
\hline \hline
\end{tabular}

To ease the control complexity and to minimize the cost of power devices, the least numbers of armature phases are purposely chosen, i.e., three-phase for MTBF operation and six-phase for STUF operation. Moreover, to simplify the manufacturing process, the least numbers of stator and rotor poles are preferred. By taking these criteria into account, the combination of $k=1, m^{\prime}=3, N^{\prime} s t=2, m^{\prime \prime}=6, N^{\prime \prime}{ }_{s t}=1, N_{s e}=12$ and $N_{r}=10$ is selected as the proposed structure. Based on this combination, the proposed EG machine is anticipated to offer high torque at the MTBF operation, and wide speed range at the STUF operation.

\section{B. Winding arrangement:}

In the previous study [24], the multi-tooth operation was achieved by connecting its multiple phases among adjacent positions. With this adjacent-position winding arrangement, the flux-linkages among the armature phases are unbalanced. Hence, the back EMF waveforms end up with asymmetry patterns, which are 
unfavorable for the torque production. In particular, the resulting asymmetric back EMF waveforms will produce large torque ripple, which associates with undesirable acoustic noise and vibration.

To improve the situation, the proposed EG machine at the MTBF operation is purposely connected with the so-called balance-position winding arrangement, i.e., A1, A2, D1 and D2 are connected in series; B1, B2, E1 and E2 in series; and C1, C2, F1 and F2 in series. Based on the proposed winding arrangement, the fluxlinkages among the armature phases are essentially balanced so that the back EMF waveforms can become more symmetric than its counterpart does.

To achieve the desired mode-switching function, the proposed machine purposely adopts the concentrated winding arrangement so that each of its armature coil can be individually connected. Hence, the proposed connection arrangement can be easily realized by using power electronic switches.

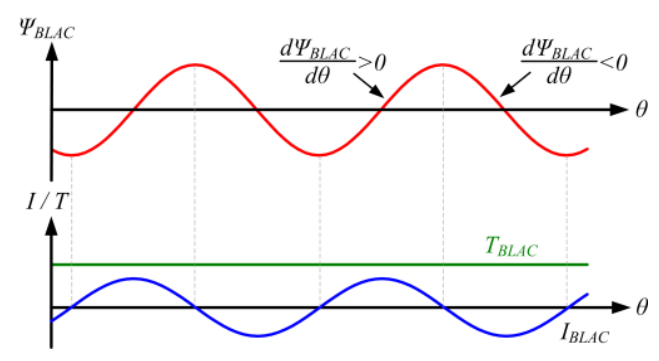

(a)

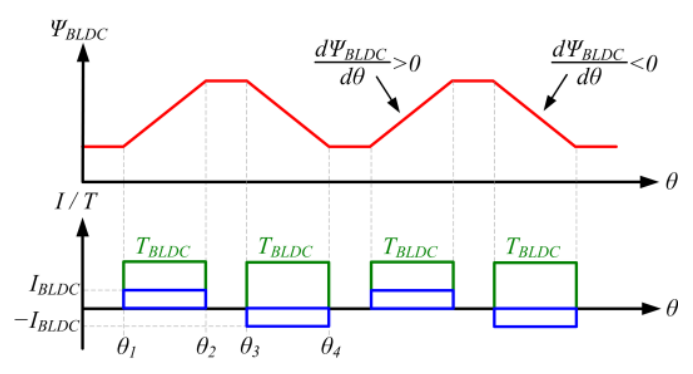

(b)

Fig. 2. Theoretical operating principles: (a) BLAC conduction scheme. (b) BLDC conduction scheme. 


\section{Back EMF waveforms:}

For EV propulsion, some important issues should be considered. Namely, the torque ripple should be minimized at the low-speed high-torque operation, while the torque density should be maximized at the highspeed low-torque operation. To take these criteria into account, the back EMF waveforms should be carefully designed.

In general, the back EMF waveform of electric machines can be classified into two main types, namely the sinusoidal-like waveform and the trapezoidal-like waveform. To effectively operate these machines, there are two conduction schemes available, namely the brushless AC (BLAC) scheme for the sinusoidal-wave machine and the brushless DC (BLDC) scheme for the trapezoidal-wave machine, respectively.

For the sinusoidal-wave machine, in order to produce the positive electromagnetic torque $T_{B L A C}$, the sinusoidal armature current $I_{B L A C}$ is applied according to the status of the flux-linkage $\Psi_{B L A C}$ that is generated by the DC-field excitation. This BLAC conduction scheme is depicted in Fig. 2(a). By using this scheme, the sinusoidal-wave machine can match the injected armature current with its back EMF waveform, hence achieving the minimized torque ripple performance.

For the trapezoidal-wave machine, a positive rectangular current $I_{B L D C}$ is applied to the armature winding when the flux-linkage $\Psi_{B L D C}$ is increasing so as to produce the positive torque $T_{B L D C}$. Meanwhile, a negative current is instead applied to the armature winding when the flux-linkage is decreasing so as to produce also the positive torque. This BLDC conduction scheme is depicted in Fig. 2(b). According to the interaction between back EMF and current waveforms, the trapezoidal-wave machine with $I_{B L D C}$ can generate higher output power than the sinusoidal-wave machine with $I_{B L A C}[4]$. Hence, the BLDC conduction scheme can offer higher torque density than its BLAC counterpart does.

\section{Operating principles:}

According to the aforementioned discussion, the proposed EG machine should be designed in such a way that the back EMF waveform is in between sinusoidal-like and trapezoidal-like patterns. Based on this design 
criterion, the proposed machine at the MTBF operation can operate similarly as the sinusoidal-wave machine does so that the torque with minimized ripple can be achieved at the low-speed situation. Meanwhile, the proposed machine at the STUF operation can instead operate similarly as the trapezoidal-wave machine does so that the improved torque density can be provided at the high-speed situation.

At the MTBF operation, the proposed machine behaves similarly as the three-phase synchronous machine does. Thus, it adopts the BLAC scheme with the three-phase armature currents as given by:

$$
\left\{\begin{array}{l}
i_{a}=I_{\text {MTBF }} \sin \theta \\
i_{b}=I_{\text {MTBF }} \sin (\theta-(2 \pi / 3)) \\
i_{c}=I_{\text {MTBF }} \sin (\theta+(2 \pi / 3))
\end{array}\right.
$$

where $i_{a, b, c}$ and $I_{M T B F}$ are the instantaneous and maximum values of the phase currents, respectively, at the MTBF operation.

At the STUF operation, the proposed machine behaves similarly as the six-phase DSPM machine does. This, it adopts the BLDC scheme. To maintain the same input power level as that employed in the MTBF operation, the magnitude of phase currents at the STUF operation should be reduced accordingly as given by:

$$
\begin{cases}i_{k}=I_{\text {STUF }} & \theta_{1} \leq \theta \leq \theta_{2} \\ i_{k}=0 & 0<\theta<\theta_{1}, \theta_{2}<\theta<\theta_{3}, \theta_{4}<\theta<2 \pi \\ i_{k}=-I_{\text {STUF }} & \theta_{3} \leq \theta \leq \theta_{4}\end{cases}
$$

where $i_{k}$ and $I_{S T U F}$ are the instantaneous and maximum values of the phase currents, respectively, at the STUF operation. The intervals of $\left(\theta_{1}, \theta_{2}\right)$ and $\left(\theta_{3}, \theta_{4}\right)$ refer to the rising and falling periods of flux-linkages, respectively, which are governed by the relationships between the rotor pole-arc length and the stator polearc length. According to the proposed operating principles, the EG machine can offer smoother torque at the MTBF operation, while higher torque density at the STUF operation.

\section{E. Analysis of the operating range extension:}

Unlike the PM machines, the magnetless machines can utilize its controllable DC-field excitation for flux regulation, hence offering the flux-weakening capability to extend the operating range. However, this flux- 
weakening capability has some constraints, which cannot enable the magnetless machines satisfying the desired operating range for EV application.

The flux-linkage varies with the flux regulation, i.e., when the DC-field excitation is weakened, the fluxlinkage decreases accordingly. Meanwhile, the self-inductance instead gradually increases. It should be noted the generated electromagnetic torque is contributed by two torque components, namely the DC-field torque and the reluctance torque. The former is governed by the flux-linkage, while the latter by the self-inductance [4]. Hence, at a particular point along the flux-weakening process, the DC-field torque no longer serves as the major component, while the reluctance torque will replace its dominating position. In other words, the machine should start to operate with the reluctance principle at this flux-weakening point, where only half of the torque-production zone is utilized. Upon this scenario, a larger torque ripple is resulted and a larger armature current is needed to maintain the same torque level, which are both unfavorable for EV application.

To avoid the magnetless machines switching to the reluctance operation, the DC-field excitation should be kept at certain high levels. As expected, it will limit its flux-weakening capability and hence the operating range. Therefore the proposed EG machine can fundamentally solve this dilemma, namely providing high torque and wide speed range. In addition, the proposed machine can incorporate flux-weakening operation to further extend the operating range at both the MTBF and STUP operations.

\section{F. Proposed control scheme:}

The control scheme for the proposed EG machine is shown in Fig. 3. It can be divided into five parts, namely (i) the armature controller, (ii) the armature inverters, (iii) the DC-field controller, (iv) the H-bridge converter, and (v) the EG machine. To facilitate the functionality of mode-switching, a full-bridge inverter is used on each phase. Nevertheless, with the advancement of power device technology, the cost of multiphase inverters has become economically acceptable [25]. Actually, multiphase machines with multiphase inverters are becoming attractive. They not only offer better performance but also provide faulttolerant capability to improve the reliability, which are highly desirable for EVs [4]. 


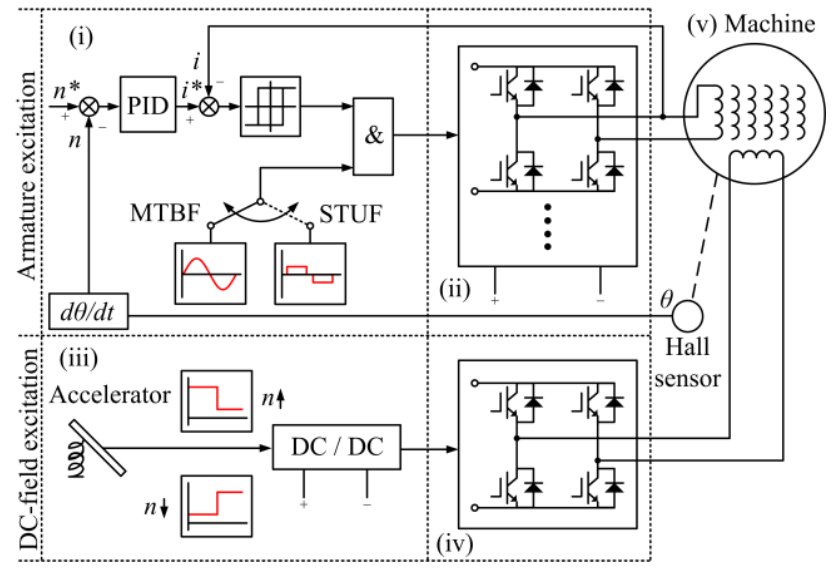

Fig. 3. Control scheme for EG operation.

The armature controller adopts the dual-closed-loop control scheme, i.e., the outer speed loop employs a PID regulator for speed control and the inner current loop adopts a hysteresis regulator for current chopping control. Based on the comparison between the speed command $n^{*}$ and the actual speed $n$, the armature current command $i^{*}$ is generated. Meanwhile, based on the comparison between $i^{*}$ and the actual current $i$, the hysteresis regulator generates the control signal. Consequently, the firing signal of each power switch in the armature inverters can be developed. In addition to the conventional dual-closed-loop control, the armature controller requires multiphase inverters to properly feed the armature windings. Namely, the armature inverters can provide the desired BLAC currents for the MTBF operation, and the desired BLDC currents for the STUF operation.

On the other hand, the DC-field excitation module consists of two major components, namely the DC/DC converter and the H-bridge converter. The DC/DC converter is used to regulate the excitation level while the H-bridge converter serves to control the direction of excitation, hence offering the desired flux regulation. 


\section{Machine Performance Analysis}

\section{A. Electromagnetic field analysis:}

To study the performance of electric machines, the FEM-based electromagnetic field analysis has been recognized as one of the most accurate and convenient tools for many years [26]. In this paper, a commercially available FEM software package, the JMAG-Designer, is adopted to perform the analysis. Hence, the corresponding machine dimensions and parameters can be optimized iteratively.

The magnetic field distribution of the proposed machine at no-load condition is shown in Fig. 4. The result shows that the flux distributions are well balanced and align with the theoretical results. Upon the DC-field excitation, the flux-linkage waveforms are shown in Fig. 5. These waveforms show that the EG machine can offer the bipolar flux-linkage at MTBF operation, and the unipolar flux-linkage at STUF operation. It is due to the fact that each armature phase produces a unipolar flux-linkage, and the series connection of two armature phases will superimpose two unipolar flux-linkages to form a bipolar pattern.

Fig. 4. Magnetic field distribution.
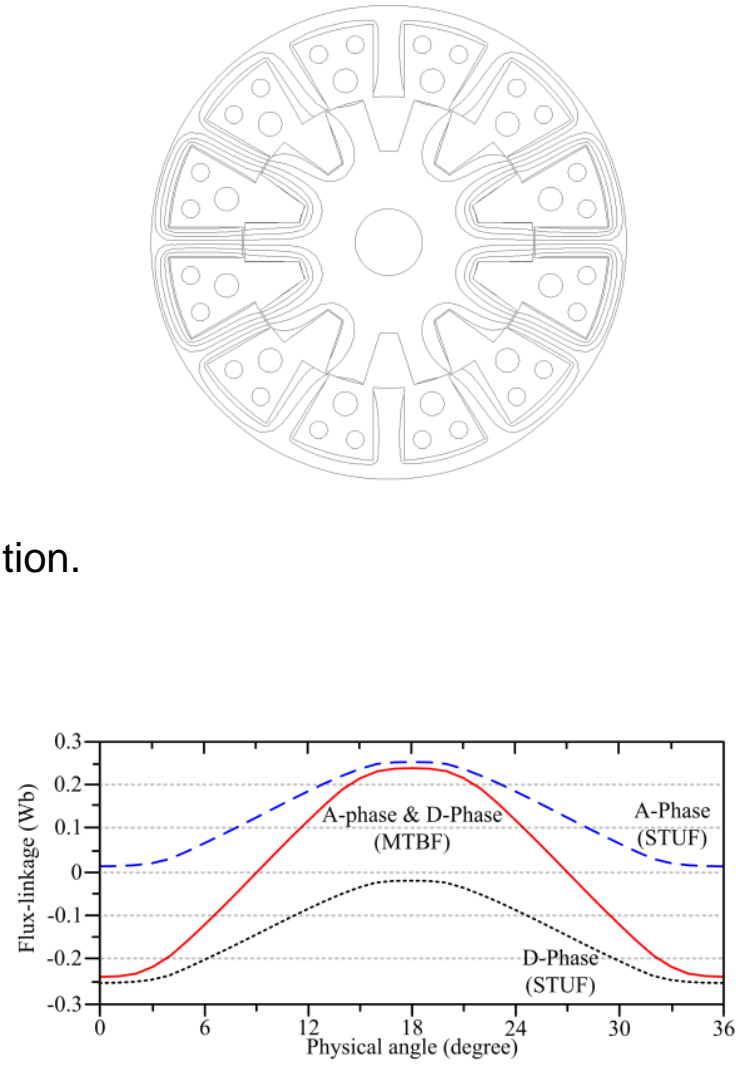

Fig. 5. Flux-linkage waveforms at two operations. 


\section{B. Pole-arc ratio analysis:}

The characteristics of the back EMF waveforms can be modified by the so-called pole-arc ratio $p$, which is defined as the ratio of the rotor pole-arc $\beta_{r}$ to the stator pole-arc $\beta_{s}$, i.e., $p=\beta_{r} / \beta_{s}$. In order to minimize the magnetic saturation and to maximize the armature slot area, $\beta_{s}$ is first set as a particular value. At the beginning, $\beta_{r}$ is selected to be equal to $\beta_{s}$, i.e., $p=1$, as shown in Fig. 6(a). Then, $p$ is modified by tuning $\beta_{r}$ in such a way that the optimal pole-arc ratio $p_{-o p t}=\beta_{r_{-} o p t} / \beta_{s}$ can be obtained as shown in Fig. 6(b).

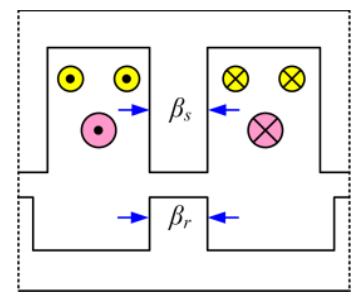

(a)

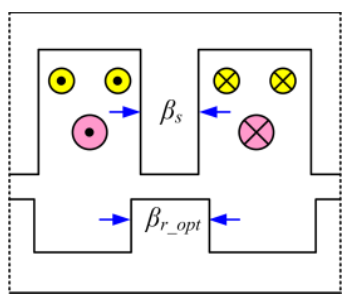

(b)

Fig. 6. Pole-arc ratio variations: (a) Primitive case. (b) Optimal case.

The variations of the back EMF waveforms according to different values of $p$ are shown in Fig. 7. As discussed, the proposed machine should be designed to offer the back EMF waveform in between the sinusoidal-like and trapezoidal-like patterns. Hence, the pole-arc ratio should be selected between $p=1.2$ and 1.3.

Borrowing from the concept of cogging torque in PM machines, the cogging torque of this machine is defined as the detent torque generated by the interaction between the stator and rotor poles upon the existence of DC-field excitation. To confirm the pole-arc ratio with the optimal performance, the cogging torque is analyzed and its waveforms under different values of $p$ are shown in Fig. 8. When $p=1.2$ and 1.3, the peak values of the cogging torque are approximately $0.23 \mathrm{Nm}$ and $0.20 \mathrm{Nm}$, respectively. Therefore, in order to achieve the desired back EMF waveform and the lower cogging torque, the optimal pole-arc ratio is selected as $p_{-}$opt $=1.3$. 


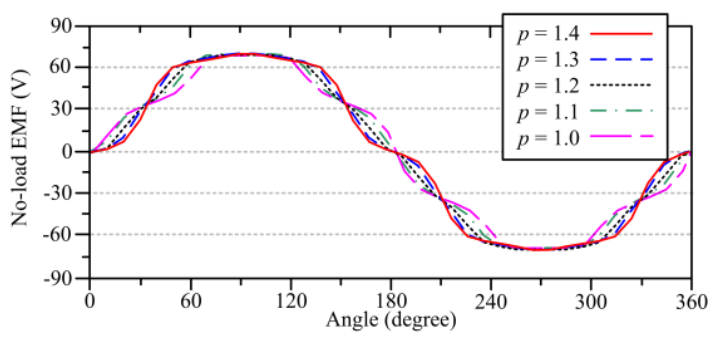

(a)

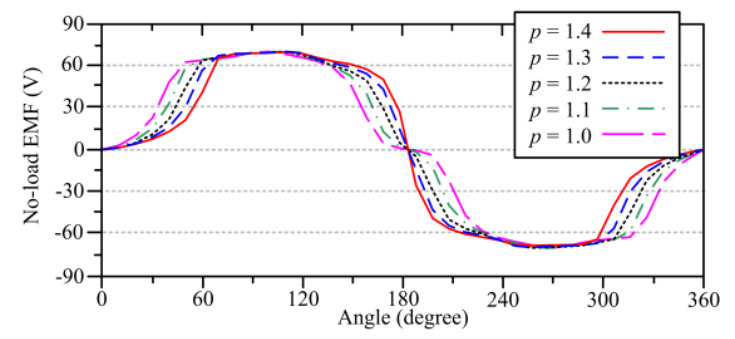

(b)

Fig. 7. Back EMF waveforms under different pole-arc ratios: (a) MTBF operation. (b) STUF operation.

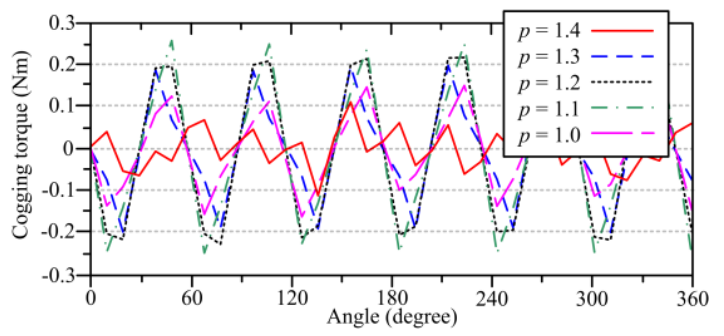

Fig. 8. Cogging torques under different pole-arc ratios.

\section{No-load EMF performances:}

By using the JMAG-Designer, the no-load EMF waveforms of the proposed EG machine under the MTBF operation at $300 \mathrm{rpm}$ and under the STUF operation at $600 \mathrm{rpm}$ are simulated as shown in Fig. 9 and Fig. 10, respectively. It can be found that the no-load EMF waveforms at the MTBF operation are of well-balanced three-phase symmetrical patterns, which confirms the effectiveness of the proposed balance-position winding arrangement. Meanwhile, the no-load EMF waveforms at the STUF operation are also well balanced with 
six-phase symmetrical patterns. The no-load EMF waveforms at both operations exhibit the patterns in between the sinusoidal-like and trapezoidal-like characteristics. Hence, both of them are suitable for both BLAC and BLDC conduction schemes.

Even though the operating speeds of the MTBF and STUF operations are different, their magnitudes of the no-load EMF waveforms are approximately the same. Hence, the results verify that the MTBF operation should be adopted at the low-speed environment, whereas the STUF operation instead at the high-speed environment.

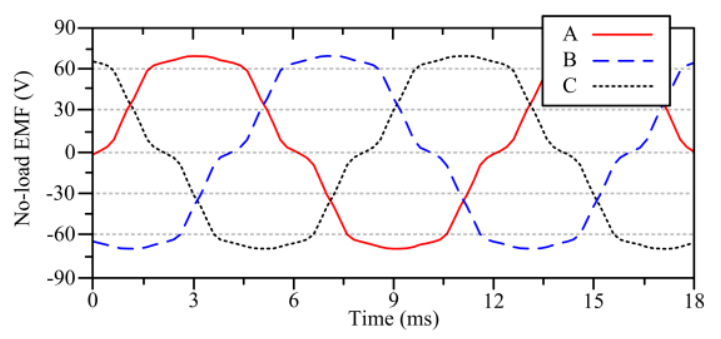

Fig. 9. Back EMF waveforms under MTBF operation at 300 rpm.

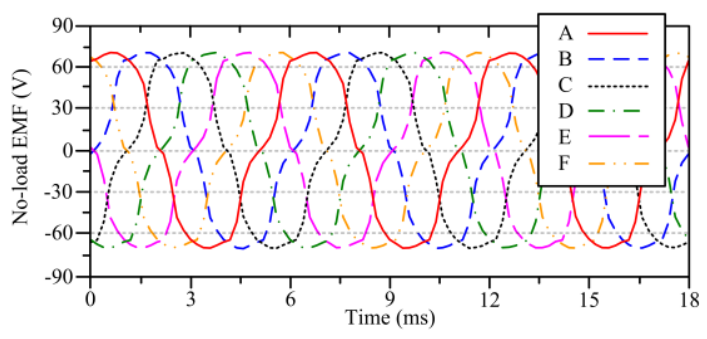

Fig. 10. Back EMF waveforms under STUF operation at 600 rpm.

\section{Torque performances:}

The torque performances of the proposed machine at the MTBF and STUF operations are computed by attaching the ideal current sources to the windings. As discussed, the BLAC and BLDC conduction schemes, i.e., the three-phase sinusoidal-like and six-phase trapezoidal-like currents, should be employed for the MTBF and the STUF operations, respectively. This case is so-called the Type I, and the corresponding torque performances are shown in Fig. 11. In order to provide a comparative analysis, another case, so-called the Type II, is realized where the MTBF operation employs the three-phase BLDC scheme while the STUF the 
six-phase BLAC scheme. The corresponding torque performances are shown in Fig. 12.

It can be observed that the average steady torques at the MTBF and STUF operations in Type I are $9.9 \mathrm{Nm}$ and 5.6 Nm, respectively; while in Type II are $10.8 \mathrm{Nm}$ and $5.0 \mathrm{Nm}$, respectively. The results confirm that the MTBF operation can achieve higher steady torques than that produced by the STUF operation. Meanwhile, the results also confirm that the STUF operation using the BLDC scheme can produce higher steady torque than that using the BLAC scheme.

In addition, the cogging torque can be computed under the no-load situation. In Type I, the cogging torques are found to be $0.2 \mathrm{Nm}$, which are only $2.1 \%$ and $3.8 \%$ of their average torques at the MTBF and STUF operations, respectively. Meanwhile, in Type II, the cogging torques are $1.9 \%$ and $4.2 \%$ of their average torques instead. All these cogging torque values are very acceptable, as compared with the PM counterparts [7].

To provide a comprehensive analysis of the torque performances, the torque ripples at the MTBF and STUF operations in Type I are found to be $9.1 \%$ and $25.9 \%$, respectively; while in Type II are $28.6 \%$ and $12.2 \%$, respectively. The results confirm that the torque ripple at the MTBF operation using the BLAC scheme is smaller than that using the BLDC scheme.

It should be noted that although the machine performance under transient conditions is essential, the scope of this paper is focused on the design and analysis of the proposed machine with the electronic gearing concept. Thus, the transient performance of the machine including closed-loop control will be the direction of our future work. 


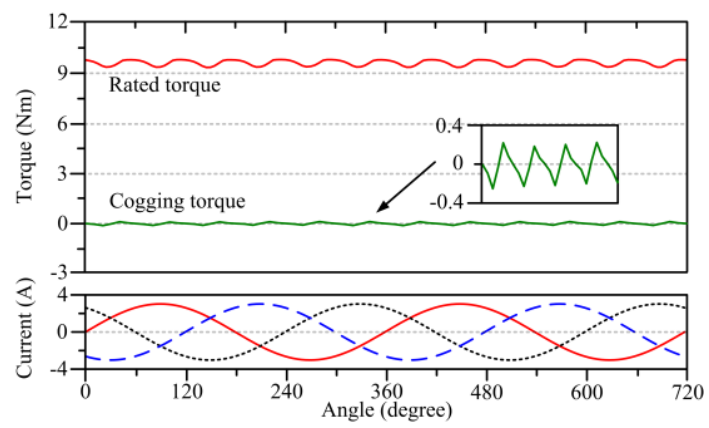

(a)

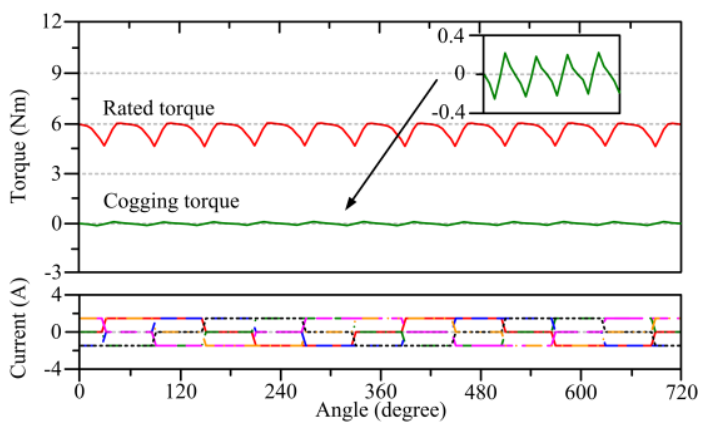

(b)

Fig. 11. Torque waveforms in Type I: (a) MTBF. (b) STUF.

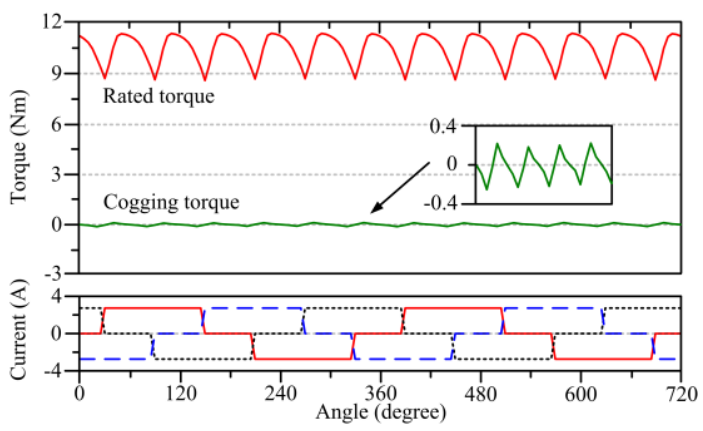

(a) 


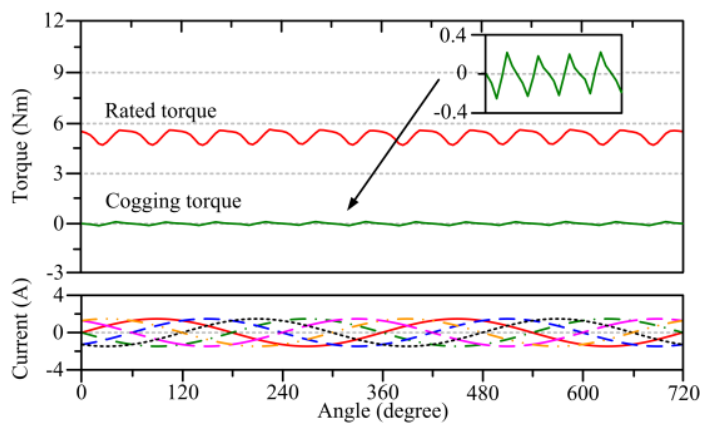

(b)

Fig. 12. Torque waveforms in Type II: (a) MTBF. (b) STUF.

Similarly, two other combinations between the two machine operations and the two conduction schemes can be performed, while they are less important. Hence, only the results in Type I and Type II are discussed and tabulated in Table II. Particularly, the proposed machine should employ the Type I operation, i.e., the MTBF operation should adopt the BLAC scheme to produce smoother torque for high-torque low-speed operation, while the STUF operation instead should adopt the BLDC scheme to achieve higher torque density for low-torque high-speed operation.

\section{E. Operating range extension performances:}

The torque-speed capability of the proposed machine is shown in Fig. 13. In order to maintain the high level of DC-field excitation, different operations are suggested for different operating ranges:

1) Within 0-300 rpm, the MTBF operation should be adopted, which works at the rated DC-field excitation, i.e., $5 \mathrm{~A} / \mathrm{mm}^{2}$.

2) Within 300-600 rpm, the MTBF operation should be adopted, which employs the flux-weakening operation.

3) At $600 \mathrm{rpm}$, the proposed machine should switch from the MTBF operation to the STUF operation, while the DC-field is regulated to its rated value, i.e., $5 \mathrm{~A} / \mathrm{mm}^{2}$.

4) Within 600-1200 rpm, the STUF operation should be adopted, which employs the flux-weakening operation. 
By incorporating flux-weakening operation into electronic gearing, the proposed machine can offer the desired wide speed range while maintaining at the high level of DC-field excitation. This can prevent the machine from operating with the reluctance principle, hence eliminating the aforementioned unwanted consequences. Thus, the proposed machine can offer the desired performances covering the whole operating range from zero to $1200 \mathrm{rpm}$, which fulfills the requirement of direct-drive application for EVs [7].

TABLE ॥

Torque Performances of Proposed Machine

\begin{tabular}{|c|c|c|c|c|}
\hline \multirow{2}{*}{ Item } & \multicolumn{2}{|c|}{ Type I } & \multicolumn{2}{|c|}{ Type II } \\
\hline & MTBF & STUF & MTBF & STUF \\
\hline $\begin{array}{l}\text { Conduction } \\
\text { scheme }\end{array}$ & BLAC & BLDC & BLDC & BLAC \\
\hline No. of phases & 3 & 6 & 3 & 6 \\
\hline Average & 9.9 & 5.6 & 10.8 & 5.0 \\
\hline torque & $\mathrm{Nm}$ & $\mathrm{Nm}$ & $\mathrm{Nm}$ & $\mathrm{Nm}$ \\
\hline $\begin{array}{l}\text { Cogging } \\
\text { torque }\end{array}$ & $2.1 \%$ & $3.8 \%$ & $1.9 \%$ & $4.2 \%$ \\
\hline Torque ripple & $9.1 \%$ & $\begin{array}{c}25.9 \\
\%\end{array}$ & $\begin{array}{c}28.6 \\
\%\end{array}$ & $\begin{array}{c}12.2 \\
\%\end{array}$ \\
\hline
\end{tabular}

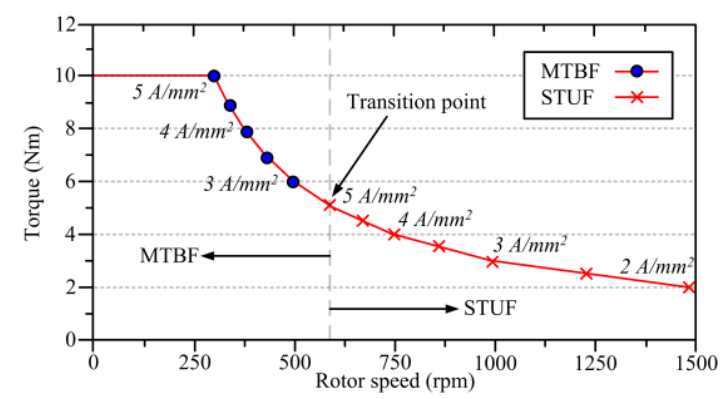


Fig. 13. Torque-speed capability.

\section{EXPERIMENTAL VERIFICATIONS}

To experimentally verify the proposed electronic gearing concept, the prototype of the proposed machine is designed and built as shown in Fig. 14. The experimental setup mainly includes the EG machine prototype, dynamometer, driver, digital oscilloscope, torque sensor, rectifier, and DC power supply. Although the machine designed for a typical passenger EV is generally over $40 \mathrm{~kW}$ [14], the power and torque levels of the proposed machine prototype are purposely scaled down so as to ease practical experimentation in the laboratory. The corresponding key design data is listed in Table III.

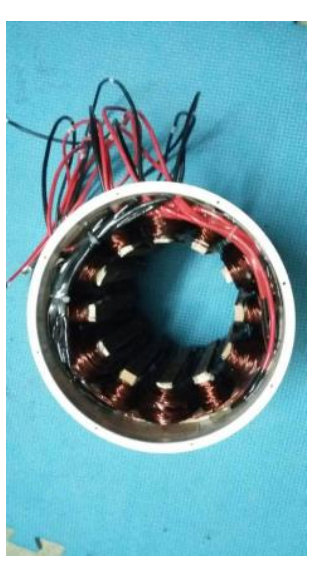

(a)

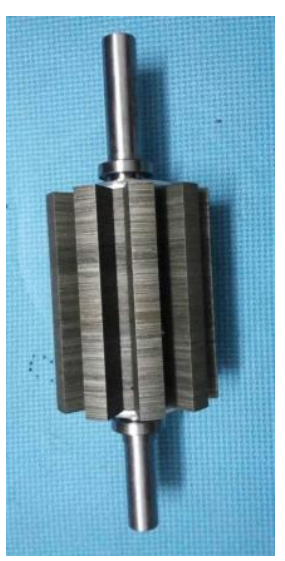

(b)

Fig. 14. Machine prototype: (a) Stator. (b) Rotor.

TABLE III

Key Design Data of Proposed Machine

\begin{tabular}{lcc}
\hline \hline Item & Value \\
\hline Stator & outside & $156.0 \mathrm{~mm}$ \\
diameter & & \\
& & \\
\end{tabular}




\begin{tabular}{lcc} 
Stator inside & $96.0 \mathrm{~mm}$ \\
diameter & \\
Rotor outside & $95.0 \mathrm{~mm}$ \\
diameter & \\
Rotor $\quad$ inside & $22.0 \mathrm{~mm}$ \\
diameter & \\
No. of stator poles & 12 \\
No. of rotor poles & 10 \\
Stator pole arc & $12.0^{\circ}$ \\
Rotor pole arc & $15.6^{\circ}$ \\
Airgap length & $0.5 \mathrm{~mm}$ \\
Stack length & $120 \mathrm{~mm}$ \\
No. of turns per & 110 \\
armature coil & \\
\hline \hline
\end{tabular}

The measured no-load EMF waveforms of the proposed machine under the MTBF operation at $300 \mathrm{rpm}$ and under the STUF operation at $600 \mathrm{rpm}$ are shown in Fig. 15 and Fig. 16, respectively. Since all the noload EMF waveforms of the 6-phase windings at the STUF operation are well balanced, only three phases (A-phase, C-phase and E-phase) are shown so as to achieve better presentation. As expected, the measured waveforms well agree with the simulated results as shown in Fig. 9 and Fig. 10, respectively. Those slight discrepancies are essentially due to the end-effect and manufacturing imperfection. Meanwhile, the measured magnitudes of the no-load EMF waveforms well comply with the theoretical ones so that the discrepancies are very acceptable.

Moreover, the measured no-load EMF waveforms under MTBF operation at $500 \mathrm{rpm}$ and under STUF operation at $1000 \mathrm{rpm}$, without and with the DC-field flux regulation, are shown in Fig. 17, and Fig. 18, 
respectively. With the use of flux-weakening capability, the magnitudes of the no-load EMF waveforms at higher speeds can be maintained at the same level as those at lower speeds. These waveforms confirm that the proposed machine possesses the capability of flux regulation under both the MTBF and STUF operations. Consequently, these results verify that the proposed machine can operate over a wide speed range.

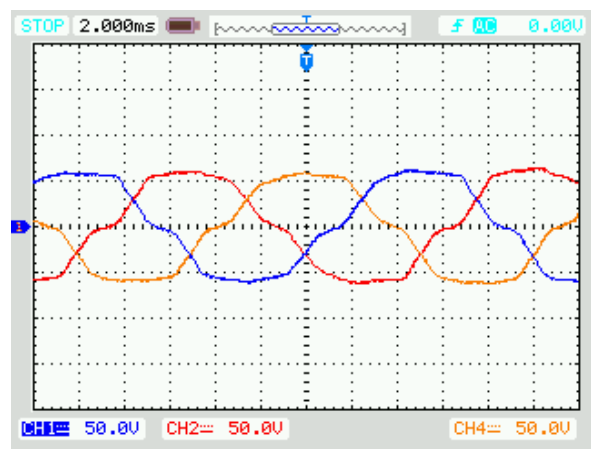

Fig. 15. Measured no-load EMF waveforms under MTBF operation at 300 rpm and 5 A excitation (50 V/div).

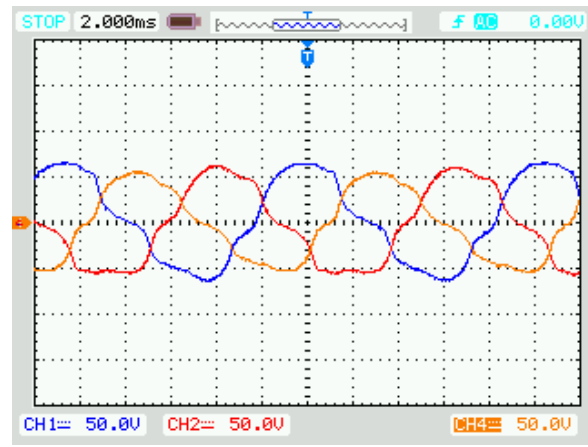

Fig. 16. Measured no-load EMF waveforms under STUF operation at 600 rpm and 5 A excitation (50 V/div). 


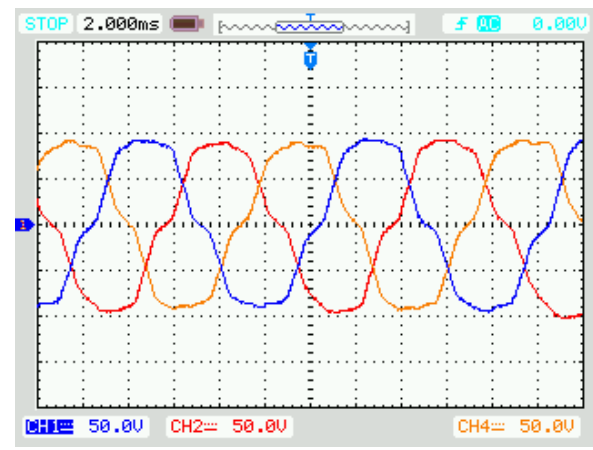

(a)

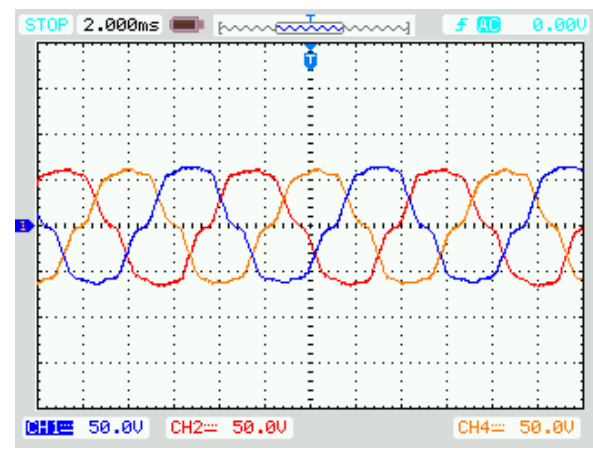

(b)

Fig. 17. Measured no-load EMF waveforms under MTBF operation at $500 \mathrm{rpm}$ (50 V/div): (a) Without flux regulation. (b) With flux regulation.

Upon the rectification under the open-circuit condition, the corresponding simulated and measured mean voltage characteristics with respect to different DC-field excitations under the MTBF operation at $300 \mathrm{rpm}$ and under the STUF operation at $600 \mathrm{rpm}$ are shown in Fig. 19. In particular, with the use of an external rectifier circuit, the simulated characteristics can be generated. The simulation results well agree with the measured results, where the rectified output voltage can be regulated linearly based on the controllable DCfield excitation. The results verify that the proposed machine can utilize electronic gearing and flux regulation capabilities to maintain the voltage at the desired value, hence protecting the whole EV system. 


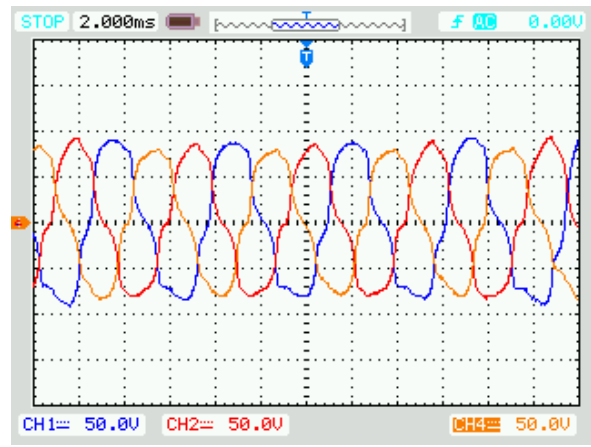

(a)

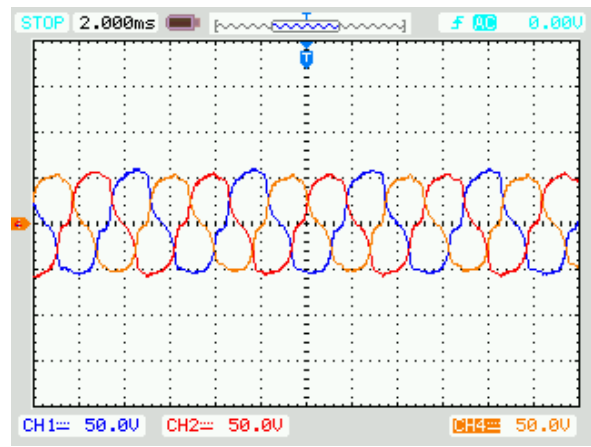

(b)

Fig. 18. Measured no-load EMF waveforms under STUF operation at $1000 \mathrm{rpm}$ (50 V/div): (a) Without flux regulation. (b) With flux regulation.

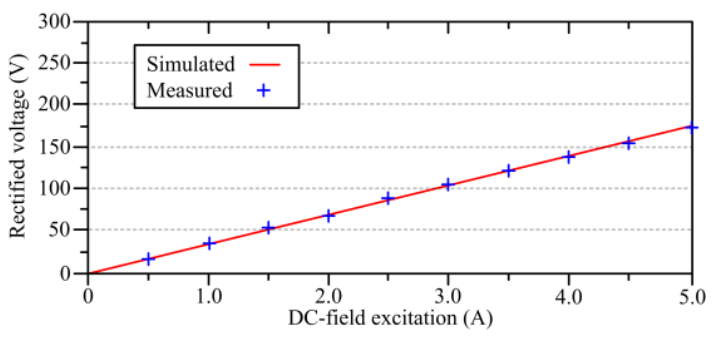

(a) 


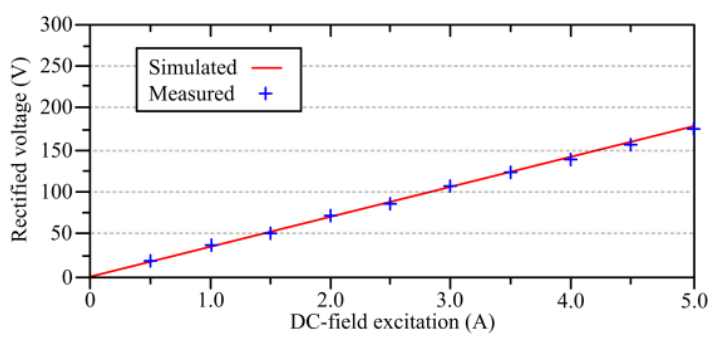

(b)

Fig. 19. Simulated and measured rectified voltage characteristics under different DC-field excitations: (a) MTBF operation at $300 \mathrm{rpm}$. (b) STUF operation at $600 \mathrm{rpm}$.

Furthermore, the simulated and measured torque characteristics with respect to different armature currents under the two operations with the DC-field excitation of 2 A are shown in Fig. 20. To obtain the average torques at the MTBF operation, the armature windings are fed by the current sources with the relationship of $i_{a}=-2 i_{b}=-2 i_{c}$. Also, the average torques at the STUF operation can be obtained based on the similar approach. It can be observed that the measured torques well agree with the simulated values. There is a minor discrepancy that the measured torques are slightly smaller than the simulated ones, which is actually due to the presence of end-effect.

Based on the measured results regarding to the back EMF waveforms and torque performances, they illustrate that the MTBF and STUF operations can offer the desired high-torque low-speed and low-torque high-speed operations, respectively. Hence, the electronic gearing concept of the proposed machine is verified.

Finally, as shown in Fig. 21, the efficiencies of the proposed EG machine under different load current at both the MTBF and STUF operations are measured. To be specific, the operating speeds of the MTBF and STUF operations are $500 \mathrm{rpm}$ and $1000 \mathrm{rpm}$, respectively. It can be found that the efficiencies of the proposed machine can achieve $78 \%$ at the MTBF operation and $74 \%$ at the STUF operation. Accordingly, the proposed machine working at both the MTBF and STUF operations can offer satisfactory efficiencies as compared with the commonly employed machines do [11]. 


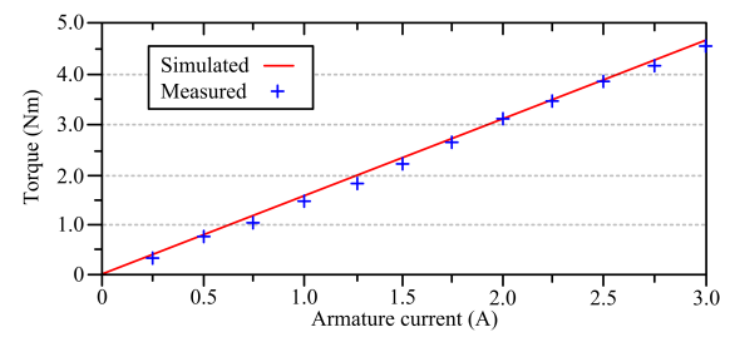

(a)

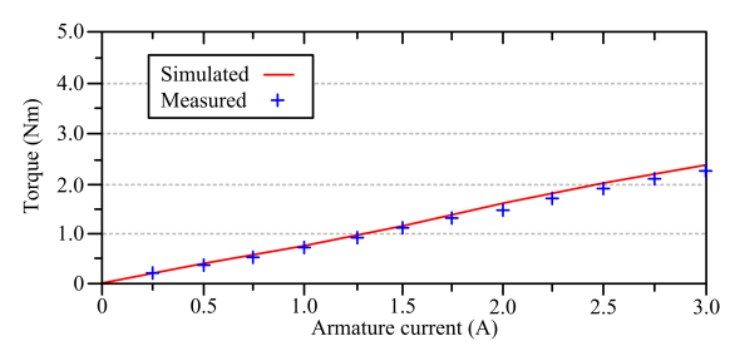

(b)

Fig. 20. Simulated and measured torque characteristics under different armature currents: (a) MTBF operation at $300 \mathrm{rpm}$. (b) STUF operation at $600 \mathrm{rpm}$.

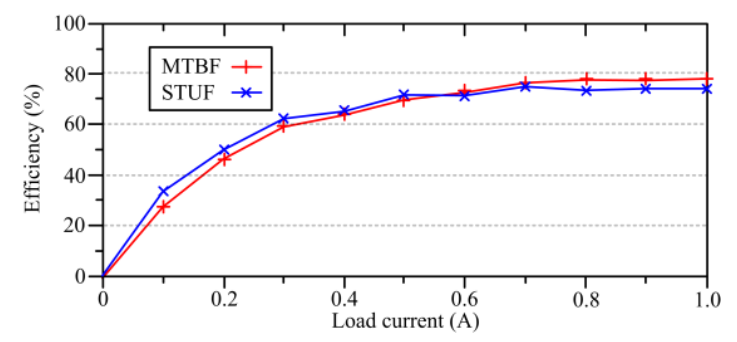

Fig. 21. Measured efficiencies under different load currents.

\section{CONCLUSION}

This paper has proposed a new EG magnetless machine for EV application. The balance-position winding arrangement is also proposed and implemented to solve the problem of unbalanced flux-linkages and the associated high torque ripple. The design criteria of the proposed machine in terms of back EMF waveforms are discussed, leading to deduce the MTBF and STUF operations. Hence, it can perform the MTBF operation 
to achieve smoother torque at the low-speed high-torque (so-called the low-gear) situation, and perform the STUF operation to achieve higher torque density at the high-speed low-torque (so-called the high-gear) situation. By employing this electronic gearing concept and the DC-field regulation, the proposed machine can effectively extend its operating range to fulfill the demanding requirement for EVs.

\section{REFERENCES}

[1] K. T. Chau, and C. C. Chan, "Emerging energy-efficient technologies for hybrid electric vehicles," Proc. IEEE, vol. 95, no. 4, pp. 821-835, Apr. 2007

[2] A. Emadi, Y. J. Lee, and K. Rajashekara, "Power electronics and motor drives in electric, hybrid electric, and plug-in hybrid electric vehicles," IEEE Trans. Ind. Electron., vol. 55, no. 6, pp. 2237-2245, Jun. 2008.

[3] A. Y. Saber, and G. K. Venayagamoorthy, "Plug-in vehicles and renewable energy sources for cost and emission reductions," IEEE Trans. Ind. Electron., vol. 58, no. 4, pp. 1229-1238, Apr. 2011.

[4] K. T. Chau, Electric Vehicle Machines and Drives - Design, Analysis and Application. Wiley-IEEE Press, 2015.

[5] M. Ehsani, K. M. Rahman, and H. A. Toliyat, "Propulsion system design of electric and hybrid vehicles," IEEE Trans. Ind. Electron., vol. 44, no. 1, pp. 19-27, Feb. 1997.

[6] Z. Q. Zhu, and D. Howe, "Electrical machines and drives for electric, hybrid, and fuel cell vehicles," Proc. IEEE, vol. 95, no. 4, pp. 746-765, Apr. 2007.

[7] K. T. Chau, C. C. Chan, and C. Liu, "Overview of permanent-magnet brushless drives for electric and hybrid electric vehicles," IEEE Trans. Ind. Electron., vol. 55, no. 6, pp. 2246-2257, Jun. 2008.

[8] A. Tenconi, S. Vaschetto, and A. Vigliani, "Electrical machines for high-speed applications: Design considerations and tradeoffs," IEEE Trans. Ind. Electron., vol. 61, no. 6, pp. 3022-3029, Jun. 2014.

[9] Y. Fan, K. T. Chau, and M. Cheng, "A new three-phase doubly salient permanent magnet machine for wind power generation," IEEE Trans. Ind. Appl., vol. 42, no. 1, pp. 53-60, Jan./Feb. 2006. 
[10]C. Yu, and K. T. Chau, "Design, analysis, and control of DC-field memory motors," IEEE Trans. Energy Convers., vol. 26, no. 2, pp. 479-489, Jun. 2011.

[11]M. Cheng, W. Hua, J. Zhang, and W. Zhao, "Overview of stator-permanent magnet brushless machines," IEEE Trans. Ind. Electron., vol. 58, no. 11, pp. 5087-5101, Nov. 2011.

[12]Z. Zhang, Y. Tao, and Y. Yan, "Investigation of a new topology of hybrid excitation doubly salient brushless DC generator,” IEEE Trans. Ind. Electron., vol. 59, no. 6, pp. 2550-2556, Jun. 2012.

[13]J. T. Chen, and Z. Q. Zhu, "Winding configurations and optimal stator and rotor pole combination of flux-switching PM brushless AC machines," IEEE Trans. Energy Convers., vol. 25, no. 2, pp. 293-302, Jun. 2010.

[14]R. Cao, C. Mi, and M. Cheng, "Quantitative comparison of flux-switching permanent-magnet motors with interior permanent magnet motor for EV, HEV, and PHEV applications,” IEEE Trans. Magn., vol. 48, no. 8, pp. 2374-2384, Aug. 2012.

[15]R. P Deodhar, A. Pride, S. Iwasaki, and J. J. Bremner, "Performance improvement in flux-switching PM machines using flux diverters," IEEE Trans. Ind. Appl., vol. 50, no. 2, pp. 937-978, Mar./Apr. 2014.

[16]B. Gaussens, E. Hoang, M. Lecrivain, P. Manfe, and M. Gabsi, “A hybrid-excited flux-switching machine for high-speed DC-alternator applications," IEEE Trans. Ind. Electron., vol. 61, no. 6, pp. 29762989, Jun. 2014.

[17]V. Ostovic, "Pole-changing permanent-magnet machines," IEEE Trans. Ind. Appl., vol. 38, no. 6, pp. 1493-1499, Nov./Dec. 2002.

[18]D. Wang, H. Lin, H. Yang, Y. Zhang, and X. Lu, "Design and analysis of a variable-flux pole-changing permanent magnet memory machine," IEEE Trans. Magn., vol. 51, no. 11, p. 8113004, Nov. 2015.

[19]R. Dutta, and M. F. Rahman, "Design and analysis of an interior permanent magnet (IPM) machine with very wide constant power operation range," IEEE Trans. Energy Convers., vol. 23, no. 1, pp. 25-33, Mar. 2008. 
[20]I. Boldea, L. N. Tutelea, L. Parsa, and D. Dorrell, “Automotive electric propulsion systems with reduced or no permanent magnets: An overview," IEEE Trans. Ind. Electron., vol. 61, no. 10, pp. 5696-5711, Oct. 2014.

[21]A. V. Sant, V. Khadkikar, W. Xiao, and H. H. Zeineldin, "Four-axis vector-controlled dual-rotor PMSM for plug-in electric vehicles," IEEE Trans. Ind. Electron., vol. 62, no. 5, pp. 3202-3212, May 2015.

[22]D. Dorrell, L. Parsa, and I. Boldea," "Automotive electric motors, generators, and actuator drive systems with reduced or no permanent magnets and innovative design concepts," IEEE Trans. Ind. Electron., vol. 61, no. 10, pp. 5693-5695, Oct. 2014.

[23]C. H. T. Lee, K. T. Chau, and C. Liu, "Design and analysis of a cost-effective magnetless multi-phase flux-reversal DC-field machine for wind power generation," IEEE Trans. Energy Convers., vol. 30, no. 4, pp. 1565-1573, Dec. 2015.

[24]C. H. T. Lee, K. T. Chau, and C. Liu, "Design and analysis of a dual-mode flux-switching doubly salient DC-field magnetless machine for wind power harvesting," IET Renew. Power Gener., vol. 9, no. 8, pp. 908-915, Apr. 2015.

[25]E. Levi, F. Barrero, and M. J. Duran, “Multiphase machines and drives - Revisited,” IEEE Trans. Ind. Electron., vol. 63, no.1, pp. 429-432, Jan, 2016.

[26]L. Li, W. N. Fu, S. L. Ho, S. Niu, and Y. Li, “A quantitative comparison of power-electronic-driven fluxmodulated machines using magnetic field and thermal field co-simulation," IEEE Trans. Ind. Electron., vol. 62, no. 10, pp. 6076-6084, Oct. 2015.

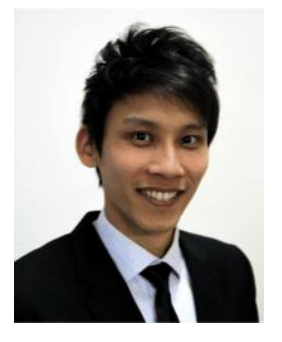

Christopher H. T. Lee (M'12) received the B.Eng. (First Class Honours) degree in electrical engineering from Department of Electrical and Electronic Engineering, The University of Hong Kong, Hong Kong, in 2009. He has been working toward the Ph.D. degree since 2011.

During the Ph.D. study, he was co-supervised by Prof. K. T. Chau and Prof. C. C. Chan. His 
research interests are Electric Machines and Drives, Renewable Energies, and Electric Vehicle Technologies. In these areas, he has published about 30 technical papers. Mr. Lee received the Croucher Foundation Fellowship 2016/2017 to support his postdoctoral research.

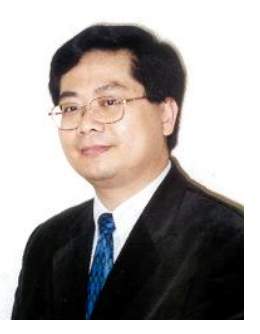

K. T. Chau (F'13) received his B.Sc. (Eng.) degree with First Class Honours, M.Phil. degree, and Ph.D. degree all in Electrical \& Electronic Engineering from The University of Hong Kong. He joined the alma mater in 1995, and currently serves as Professor in the Department of Electrical \& Electronic Engineering. His main research interests are Electric Vehicle Technologies, Renewable Energy Systems, and Machines and Drives. In these areas, he has published 4 books, 7 book chapters, and over 250 refereed journal papers.

He is also Fellow of the IET, and HKIE. He has served as chairs and organizing committee members for many international conferences, especially in the area of Electric Vehicle Technologies. Professor Chau has received many awards, including the Chang Jiang Chair Professorship, the Environmental Excellence in Transportation Award for Education, Training and Public Awareness, and the Award for Innovative Excellence in Teaching, Learning and Technology.

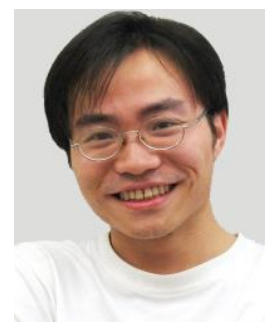

Chunhua Liu (SM'15) received the B.Eng., M.Eng. and Ph.D. degrees from Department of Automatic Control, Beijing Institute of Technology, China, and Department of Electrical and Electronic Engineering, The University of Hong Kong, Hong Kong, in 2002, 2005 and 2009, respectively. Currently, he serves as an Assistant Professor with the School of Energy and Environment, City University of Hong Kong, Hong Kong.

His research interests are in the areas of energy conversion, integration, and distribution, including electric drives, electric vehicles, renewable energy, vehicle to grid (V2G), microgrid, and 
smart grid. He currently focuses on the vehicle to grid for smart energy distribution, permanentmagnet brushless machines for sustainable energy conversion, and renewable energies for integration to smart grid. He is the author of more than 100 referred technical papers. 